\title{
MÉTODOS DE PROTEÇÃO DE ENXERTO NA PRODUÇÃO DE MUDAS DE MANGUEIRA, ABACATEIRO E NOGUEIRA-MACADÂMIA ${ }^{1}$
}

\author{
ANGELO PEDRO JACOMINO², KEIGO MINAMI², RICARDO ALFREDO KLUGE² e ANTÔNIO YOSHIO KISHINO ${ }^{3}$
}

\begin{abstract}
RESUMO - Diferentes materiais de proteção do enxerto foram avaliados na produção de mudas de mangueira (Mangifera indica L.) cv. Tommy Atkins, abacateiro (Persea americana L.) cv. Fortuna e nogueira-macadâmia (Macadamia integrifolia Maiden \& Betche) cv. Kau 344. Os materiais utilizados foram: saco de polietileno, parafina, parafina + vaselina, cera de abelha, parafilme e filme de PVC. Verificou-se que o parafilme promoveu melhor resultado de pegamento do enxerto em abacateiro $(80,3 \%)$ e nogueira-macadâmia $(74,1 \%)$, seguido pelo filme de PVC (53,4\% e 41,7\%, respectivamente). Na enxertia de mangueira, o parafilme, filme de PVC e saco de polietileno não diferiram entre si estatisticamente $(59,6 \%, 50,2 \%$ e $50,2 \%$, respectivamente). Os porcentuais de pegamento observados nos tratamentos com parafina, parafina + vaselina e cera de abelha foram baixos, em comparação com o melhor tratamento (parafilme). Nas mudas de nogueira-macadâmia o parafilme promoveu melhor desenvolvimento das brotações, além de desprender-se naturalmente dos enxertos. Conclui-se que na enxertia de mangueira os garfos podem ser protegidos com parafilme, filme de PVC ou saco de polietileno; na enxertia de abacateiro, pode-se utilizar parafilme ou filme de PVC, e na enxertia de nogueira-macadâmia deve-se optar pelo parafilme.
\end{abstract}

Termos para indexação: material para enxerto, parafilme, filme de PVC, saco de polietileno, parafina, cera de abelha, Mangifera indica, Persea americana, Macadamia integrifolia.

\author{
METHODS OF GRAFT PROTECTION IN THE PRODUCTION \\ OF MANGO, AVOCADO AND MACADAMIA NUT NURSERY TREES
}

\begin{abstract}
Different methods of graft protection were used in the production of nursery trees of mango (Mangifera indica L.) cv. Tommy Atkins, avocado (Persea americana L.) cv. Fortuna and macadamia nut (Macadamia integrifolia Maiden \& Betche) cv. Kau 344. The materials used were polyethylene bag, paraffin, paraffin + vaseline, beeswax, parafilm and PVC film. It was verified that the parafilm promoted more successful grafts in avocados (80.3\%) and macadamia nut (74.1\%), followed by PVC film (53.4\% and $41.7 \%$, respectively). On the grafting of mango plants the parafilm, PVC film or polyethylene bags did not promote statistic difference to each other $(59.6 \%, 50.2 \%$ and $50.2 \%$, respectively). The rates of successful grafts to other materials were low if compared with the best treatment (parafilm). The parafilm promoted the best growing of the sprouts in macadamia nursery trees, besides coming off naturally of the grafts. It is concluded that in the mango grafting, the graft can be protected by parafilm, PVC film or polyethylene bags; in the avocado grafting, parafilm or PVC film can be used and in the macadamia grafting the parafilm must be preferred.
\end{abstract}

Index terms: grafting materials, parafilm, PVC film, polyethylene bags, paraffin, beeswax, Mangifera indica, Persea americana, Macadamia integrifolia.

\footnotetext{
${ }^{1}$ Aceito para publicação em 26 de julho de 1999.

${ }^{2}$ Eng. Agrôn., Dr., Departamento de Produção Vegetal, Escola Superior de Agricultura Luiz de Queiroz (ESALQ), Caixa Postal 9, CEP 13418-900 Piracicaba, SP

E-mail: jacomino@carpa.ciagri.usp.br

${ }^{3}$ Eng. Agrôn., M.Sc., Instituto Agronômico do Paraná (IAPAR), Caixa Postal 481, CEP 86001-970 Londrina, PR. E-mail: akishino@pr.gov.br
}

\section{INTRODUÇÃO}

Embora a maioria das fruteiras possam ser propagadas por semente, a propagação vegetativa é, normalmente, mais utilizada. Entre os métodos de propagação vegetativa, destaca-se a enxertia, muito empregada na produção de mudas de fruteiras, por diversas razões (Browse, 1979; Hartmann et al., 1990). 
Para a multiplicação da mangueira (Mangifera indica L.), abacateiro (Persea americana L.) e nogueira-macadâmia (Macadamia integrifolia Maiden \& Betche), utiliza-se a enxertia do tipo garfagem (Cunha et al., 1994; Simão, 1998).

O sucesso da enxertia depende do conhecimento da técnica, da habilidade do enxertador, das condições da planta e do ambiente, e de outros fatores. Um cuidado especial diz respeito à proteção do enxerto contra a desidratação após a operação, principalmente quando se trata de enxertia por garfagem (Hartmann et al., 1990). O sistema de proteção tradicionalmente utilizado na enxertia por garfagem é o de sacos de polietileno transparente, colocados de boca para baixo, para proteger o enxerto, e extremidade aberta amarrada ao caule do porta-enxerto, de maneira a formar uma câmara úmida ao redor do garfo enxertado (Sampaio, 1990; Simão, 1998). Hartmann et al. (1990) relataram outros materiais que também podem ser utilizados para a proteção do enxerto na produção de mudas, tais como cera aquecida, cera de abelha e óleos. White et al. (1983), trabalhando com enxertia em pinheiro (Pinus sp.), aplicaram parafina sobre o enxerto, em substituição ao sistema tradicional em que se utilizava polietileno e papel, observando que, além da taxa de pegamento satisfatória, houve significativa redução dos custos e da quantidade de material utilizado. Bruckner et al. (1991) relataram resultados de experimento de enxertia com nogueiramacadâmia em que os garfos foram recobertos com uma fina camada de parafina, obtida por imersão dos mesmos em parafina líquida à temperatura ligeiramente superior ao ponto de fusão. O tratamento foi adequado para prevenir o ressecamento dos garfos e permitiu bom pegamento dos enxertos sob diferentes métodos de enxertia em mudas formadas no campo.

Testes preliminares realizados no Instituto Agronômico do Paraná (IAPAR) indicaram que a parafinagem de garfos lenhosos é viável também para enxertia de videira, ameixeira, caquizeiro, pereira, pessegueiro, nectarineira e quiwi. A parafina se funde à temperatura de aproximadamente $60^{\circ} \mathrm{C}$, porém atinge consistência adequada para parafinagem de estacas/ garfos a partir de $80^{\circ} \mathrm{C}$. Nesta temperatura, obtém-se uma fina camada do produto sobre o material, que não se desprende do ramo até que se inicie a brotação.
Comportamento semelhante no que diz respeito ao ponto de fusão e temperatura adequada para utilização foi verificado com cera de abelha pura.

A parafina é um hidrocarboneto com alto ponto de fusão e que pode ser misturada a hidrocarbonetos de menor ponto de fusão, como a vaselina, originando produto com ponto de fusão e consistência intermediários. Testes preliminares indicam que uma mistura de $65 \%$ de parafina e $35 \%$ de vaselina sólida pode ser utilizada para parafinagem de garfos a temperaturas entre $70^{\circ} \mathrm{C}$ e $80^{\circ} \mathrm{C}$.

O parafilme é um material à prova d'água, bastante flexível e maleável, que é aplicado sobre o local a ser protegido, de forma a proporcionar cobertura adequada e ajustar-se às formas do enxerto. Davies Junior et al. (1986) também obtiveram excelentes resultados quando utilizaram fitas de parafilme no processo de enxertia de roseiras, nos Estados Unidos.

O filme de PVC (polivinil cloreto) é um material relativamente novo que vem sendo empregado com diferentes finalidades. Com espessura geralmente entre 15 e 20 micras, esticável e auto-aderente, apresenta características específicas de permeabilidade a gases e evita a perda de água.

O objetivo deste trabalho foi verificar o efeito de diferentes materiais de proteção do enxerto na formação de mudas de mangueira, abacateiro e nogueira-macadâmia, visando indicar ao viveirista/agricultor outras opções além do saco de polietileno.

\section{MATERIAL E MÉTODOS}

Este trabalho foi composto de três experimentos conduzidos no Departamento de Produção Vegetal da Escola Superior de Agricultura "Luiz de Queiroz" - ESALQ/USP, em Piracicaba, SP, e no viveiro de produção de mudas da Estância Macadâmia, em Dois Córregos, SP.

As sementes utilizadas para a produção dos portaenxertos de mangueira foram obtidas de frutos maduros de plantas matrizes da cultivar Espada. Após secagem à sombra e retirada do endocarpo, as sementes foram semeadas diretamente em recipientes, colocadas com a face ventral voltada para baixo e cobertas com uma fina camada de terra peneirada e cobertura morta. A enxertia foi realizada quando os porta-enxertos apresentavam o caule com diâmetro aproximado de $1,0 \mathrm{~cm}$. Os garfos foram colhidos de planta da cultivar Tommy Atkins e enxertados no mesmo dia, utilizando-se enxertia do tipo garfagem de topo em fenda cheia. 
As sementes utilizadas para a produção dos portaenxertos de abacateiro foram obtidas de frutos maduros de plantas matrizes da cultivar Geada. Após a lavagem e retirada da película, foram colocadas para secar à sombra e semeadas diretamente nos recipientes. A enxertia foi realizada quando os porta-enxertos apresentavam o caule com diâmetro aproximado de $1,0 \mathrm{~cm}$. Os garfos foram colhidos de planta da cultivar Fortuna e enxertados no mesmo dia, utilizando-se enxertia do tipo garfagem de topo em fenda cheia

As sementes para obtenção dos porta-enxertos de nogueira-macadâmia foram coletadas em plantas da cultivar Aloha no pomar de plantas matrizes da Estância Macadâmia. Após a retirada do carpelo, as nozes foram selecionadas por densidade em recipiente com água e semeadas em germinador de areia. Quando as mudas atingiram cerca de $12 \mathrm{~cm}$ de altura foram transplantadas para recipientes no viveiro. A enxertia foi realizada quando os porta-enxertos apresentavam caule com $0,8 \mathrm{~cm}$ de diâmetro e aspecto vigoroso. Os garfos foram coletados em plantas da cultivar Kau 344, na mesma propriedade. Utilizouse enxertia de topo do tipo inglês simples, com corte em bisel.

As mudas de todos os experimentos foram produzidas em sacos de polietileno com $30 \mathrm{~cm}$ de altura e $25 \mathrm{~cm}$ de diâmetro, contendo substrato composto de três partes de terra fértil e uma parte de esterco de curral curtido, acrescidos de três quilos de superfosfato simples e $500 \mathrm{~g}$ de cloreto de potássio por metro cúbico de substrato.

Foram avaliados os efeitos de seis tipos de material de proteção do enxerto na formação de mudas de mangueira cv. Tommy Atkins, abacateiro cv. Fortuna e nogueiramacadâmia cv. Kau 344.

Como material de proteção foram utilizados saco de polietileno, parafina, parafina + vaselina, cera de abelha, parafilme e filme de PVC. O saco de polietileno, com dimensões de 4 x $14 \mathrm{~cm}$, foi colocado de boca para baixo, cobrindo o enxerto amarrado abaixo do local da enxertia, de maneira a formar uma câmara úmida ao redor do garfo enxertado. $\mathrm{O}$ saco de proteção foi colocado imediatamente após a enxertia e retirado quando as gemas começaram a brotar. Pedaços de parafina pura foram colocados num recipiente e aquecidos em banho-maria até a fusão total. A temperatura da parafina fundida foi monitorada com auxílio de um termômetro e mantida entre $85^{\circ} \mathrm{C}$ e $90^{\circ} \mathrm{C}$. Os garfos, após retirados das plantas matrizes, foram selecionados, preparados e submetidos a uma imersão rápida (um segundo) na parafina fundida, um a um. A solidificação sobre os garfos foi bastante rápida e formou-se uma fina camada protetora. No mesmo dia foi efetuada a enxertia. Na proteção com parafina + vaselina os dois produtos foram misturados na proporção de $35 \%$ de vaselina sólida fundida e $65 \%$ de parafina fundida. $\mathrm{O}$ procedimento foi o mesmo adotado para o tratamento com parafina, sendo que neste a temperatura de aplicação ficou entre $75^{\circ} \mathrm{C}$ e $80^{\circ} \mathrm{C}$. No tratamento com cera de abelha utilizaram-se pedaços de cera de abelha pura, em vez de parafina. Todos os demais procedimentos foram idênticos aos descritos no tratamento com parafina. Na proteção com parafilme: uma fita de parafilme foi aplicada, em espiral, sobre o garfo imediatamente após a enxertia, de forma a ficar totalmente envolvido. Com filme de PVC o procedimento foi o mesmo descrito para o tratamento com parafilme.

A avaliação dos tratamentos foi após seis meses da enxertia, e foram determinadas as seguintes variáveis: pegamento do enxerto, número de brotações por enxerto, comprimento e diâmetro das brotações. Para a nogueiramacadâmia, não foi determinado o número de brotações, $\mathrm{e}$ sim o número de plantas com três brotações após a enxertia, a cada 15 dias, durante o período de seis meses. Outros aspectos, como aderência da parafina e da cera de abelha ao enxerto, e dificuldade das brotações para romper a proteção, também foram observados nas três espécies.

O delineamento experimental adotado foi em blocos casualizados, com seis tratamentos e quatro repetições, com 10 plantas por parcela. Os resultados obtidos foram submetidos a análise de variância (teste F) e teste de Tukey a $5 \%$ de probabilidade. Os dados de pegamento do enxerto foram transformados em arc sen $\sqrt{x / 100}$, e os dados de número de brotações em $\sqrt{x+0,5}$.

\section{RESULTADOS E DISCUSSÃO}

\section{Porcentagem de pegamento}

O porcentual de pegamento da enxertia nas três espécies variou entre zero e 80,26\% (Tabela 1). Essa ampla variação demonstra que houve diferença quanto à efetividade dos materiais testados na proteção dos garfos. A proteção com parafilme apresentou os melhores resultados de pegamento nas espécies estudadas. Houve diferença significativa entre este e o saco de polietileno, na enxertia de abacateiro e de nogueira-macadâmia. Os resultados obtidos com parafilme estão de acordo com as observações de Davies Junior et al. (1986), que o consideram um bom material de proteção do enxerto na produção de mudas. Este material já é utilizado comercialmente em alguns viveiros de nogueira-macadâmia no Brasil, em substituição ao saco de polietileno. Além do bom nível de pegamento do enxerto, o parafilme apresen- 
TABELA 1. Efeito de diferentes tipos de proteção do enxerto sobre o porcentual de pegamento do enxerto em mudas de mangueira 'Tommy Atkins', abacateiro 'Fortuna' e nogueira-macadâmia 'Kau 344'1.

\begin{tabular}{lccc}
\hline Proteção & \multicolumn{3}{c}{ Pegamento $(\%)^{2}$} \\
\cline { 2 - 4 } & Mangueira & Abacateiro & Macadâmia \\
\hline Saco de polietileno & $50,23 \mathrm{a}$ & $36,19 \mathrm{bc}$ & $14,93 \mathrm{c}$ \\
Parafina & $9,13 \mathrm{~b}$ & $21,57 \mathrm{bc}$ & $21,45 \mathrm{c}$ \\
Parafina + vaselina & $0,00 \mathrm{c}$ & $0,00 \mathrm{~d}$ & $0,00 \mathrm{~d}$ \\
Cera de abelha & $12,13 \mathrm{~b}$ & $11,90 \mathrm{~cd}$ & $0,00 \mathrm{~d}$ \\
Parafilme & $59,64 \mathrm{a}$ & $80,26 \mathrm{a}$ & $74,07 \mathrm{a}$ \\
Filme de PVC & $50,23 \mathrm{a}$ & $53,38 \mathrm{ab}$ & $41,69 \mathrm{~b}$ \\
\hline C.V. $(\%)$ & 18,00 & 22,55 & 17,97 \\
\hline
\end{tabular}

${ }^{1}$ Médias seguidas de mesma letra na coluna não diferem entre si pelo teste de Tukey a $5 \%$ de probabilidade.

2 Para fins de análise de variância os dados foram transformados em $\operatorname{arcsen} \sqrt{x / 100}$.

ta a vantagem de não obstruir o desenvolvimento das brotações, uma vez que se desprende naturalmente. Além disso, pode, em alguns casos, substituir a fita de plástico que é utilizada para prender o enxerto ao porta-enxerto, facilitando ainda mais a operação da enxertia. A fita de plástico, quando utilizada, requer sua retirada, para não estrangular o crescimento do caule em diâmetro.

O filme de PVC, apesar de não haver relatos de sua utilização na produção de mudas, apresentou bons resultados nas três espécies estudadas. A porcentagem de pegamento foi estatisticamente equivalente à do tratamento parafilme na enxertia de mangueira e abacateiro, e ocupou a segunda posição na enxertia de nogueira-macadâmia. As vantagens deste material são o baixo custo e a facilidade de aquisição, podendo perfeitamente ser utilizado pelos produtores de mudas, desde que tomem o cuidado de retirá-lo após o pegamento do enxerto, para não prejudicar a emissão das brotações.

A proteção do enxerto com saco de polietileno, forma tradicionalmente utilizada na enxertia de fruteiras por garfagem, apresentou baixos resultados de pegamento do enxerto, com exceção da mangueira, na qual seu desempenho foi equivalente ao dos melhores tratamentos.

Os porcentuais de pegamento observados nos tratamentos com parafina, parafina + vaselina e cera de abelha foram muito baixos, em comparação com o do melhor tratamento. Estes resultados contrariam as observações de White et al. (1983) e Bruckner et al. (1991), que verificaram boa proteção e pegamento do enxerto em outras espécies utilizando parafina. No caso da mangueira e do abacateiro, a baixa taxa de pegamento pode ter sido motivada pelas características das espécies. Enquanto nestas são utilizados como garfos os ramos ponteiros ainda em estádio de pouca lignificação (madeira mole), nas espécies estudadas por aqueles autores as partes dos ramos utilizadas como garfos encontravam-se num estádio bastante lignificado (madeira lenhosa). Isso, provavelmente, provoca maior aderência da parafina aos garfos e menor prejuízo às gemas, uma vez que naquelas espécies as gemas se encontram naturalmente protegidas por escamas nesta fase de desenvolvimento (Faust, 1989). Por outro lado, os resultados obtidos na enxertia de nogueiramacadâmia também foram baixos, o que contraria os resultados de Bruckner et al. (1991), que trabalharam com esta mesma espécie. É também possível que o baixo pegamento dos garfos submetidos às imersões (parafina, parafina + vaselina e cera de abelha) tenha sido causado pela alta temperatura necessária para ocorrer a fusão dos produtos. Embora o tempo de imersão tenha sido bastante curto (um segundo), pode ter danificado as gemas.

Outro problema observado no uso da parafina pura é o fato desta desprender-se precocemente em muitos enxertos, possibilitando a desidratação. Como a parafina forma uma camada relativamente rígida, o problema é agravado porque ao manusear-se o ramo durante a operação de enxertia, pequenas torções levam às rachaduras e ao conseqüente desprendimento da camada protetora. A adição da vaselina tornou o material mais maleável, mesmo depois de sólido, ficando aderido ao ramo por tempo indeterminado. 


\section{Número, comprimento e diâmetro das brotações}

Verificou-se pouco efeito dos tratamentos sobre o número, comprimento e diâmetro das brotações (Tabela 2). A maior influência foi verificada no comprimento das brotações de nogueira-macadâmia, nas quais as plantas com parafilme tiveram desenvolvimento bastante superior ao das demais. De maneira geral, as brotações não apresentaram dificuldade para romper a proteção de parafilme, que após 50-60 dias da enxertia começaram a desprender-se naturalmente do enxerto. Por outro lado, houve necessidade de cortar e retirar parcialmente a proteção de PVC, para possibilitar o desenvolvimento normal das brotações.
No caso da nogueira-macadâmia, não foi avaliado o número de brotações por enxerto, e sim, o tempo necessário para a emissão das três primeiras brotações. Enquanto a mangueira e o abacateiro emitem poucos brotos por enxerto, a macadâmia produz brotação intensa, exigindo desbrota freqüente para formação adequada da muda. Verificou-se que nas plantas tratadas com parafilme a emissão dos brotos foi muito mais rápida que nas demais (Fig. 1). O máximo de plantas com as três brotações foi verificado aos 60 dias após a enxertia, no tratamento com parafilme, e aos 75 dias nos demais tratamentos que emitiram brotação. Isso indica que o parafilme proporciona mais rápida cicatrização dos tecidos na região dos vasos condutores e estabelece mais rapi-

TABELA 2. Efeito de diferentes tipos de proteção do enxerto sobre o número, comprimento e diâmetro de brotações em mudas de mangueira 'Tommy Atkins', abacateiro 'Fortuna' e nogueira-macadâmia 'Kau 344'.

\begin{tabular}{lccc}
\hline Proteção & \multicolumn{3}{c}{ Brotação } \\
\cline { 2 - 4 } & Número $^{2}$ & Comprimento $(\mathrm{cm})$ & Diâmetro $(\mathrm{mm})$ \\
\hline & & Mangueira & \\
Saco de polietileno & $1,46 \mathrm{a}$ & $7,85 \mathrm{a}$ & $5,08 \mathrm{a}$ \\
Parafina & $0,74 \mathrm{a}$ & $7,36 \mathrm{a}$ & $2,36 \mathrm{c}$ \\
Parafina + vaselina & $0,00 \mathrm{~b}$ & $0,00 \mathrm{~b}$ & $2,81 \mathrm{bc}$ \\
Cera de abelha & $1,20 \mathrm{a}$ & $7,28 \mathrm{a}$ & $4,79 \mathrm{a}$ \\
Parafilme & $1,28 \mathrm{a}$ & $6,60 \mathrm{a}$ & $4,45 \mathrm{ab}$ \\
Filme de PVC & $1,10 \mathrm{a}$ & $6,40 \mathrm{a}$ & 10,37 \\
\hline C.V. (\%) & 11,92 & 16,84 & $4,26 \mathrm{a}$ \\
& & Abacateiro & $5,20 \mathrm{a}$ \\
Saco de polietileno & $3,29 \mathrm{a}$ & $8,07 \mathrm{a}$ & $0,00 \mathrm{~b}$ \\
Parafina & $2,25 \mathrm{a}$ & $8,45 \mathrm{a}$ & $2,70 \mathrm{a}$ \\
Parafina + vaselina & $0,00 \mathrm{~b}$ & $0,00 \mathrm{c}$ & $4,32 \mathrm{a}$ \\
Cera de abelha & $1,12 \mathrm{ab}$ & $2,19 \mathrm{bc}$ & $4,15 \mathrm{a}$ \\
Parafilme & $2,00 \mathrm{a}$ & $6,99 \mathrm{a}$ & 17,78 \\
Filme de PVC & $1,32 \mathrm{ab}$ & $5,14 \mathrm{ab}$ & $0,79 \mathrm{c}$ \\
\hline C.V. (\%) & 21,20 & 18,49 & $1,72 \mathrm{~b}$ \\
& & Nogueira-macadâmia & $0,00 \mathrm{~d}$ \\
Saco de polietileno & - & $1,95 \mathrm{c}$ & $0,00 \mathrm{~d}$ \\
Parafina & - & $5,13 \mathrm{~b}$ & $3,05 \mathrm{a}$ \\
Parafina + vaselina & - & $0,00 \mathrm{~d}$ & $2,94 \mathrm{a}$ \\
Cera de abelha & - & $0,00 \mathrm{~d}$ & 9,40 \\
Parafilme & - & $11,47 \mathrm{a}$ & $7,77 \mathrm{~b}$ \\
Filme de PVC & - & 12,17 &
\end{tabular}

${ }^{1}$ Médias seguidas de mesma letra na coluna não diferem entre si pelo teste de Tukey a $5 \%$ de probabilidade.

2 Para fins de análise de variância, os dados foram transformados em $\sqrt{\mathrm{x}+0,5}$. 


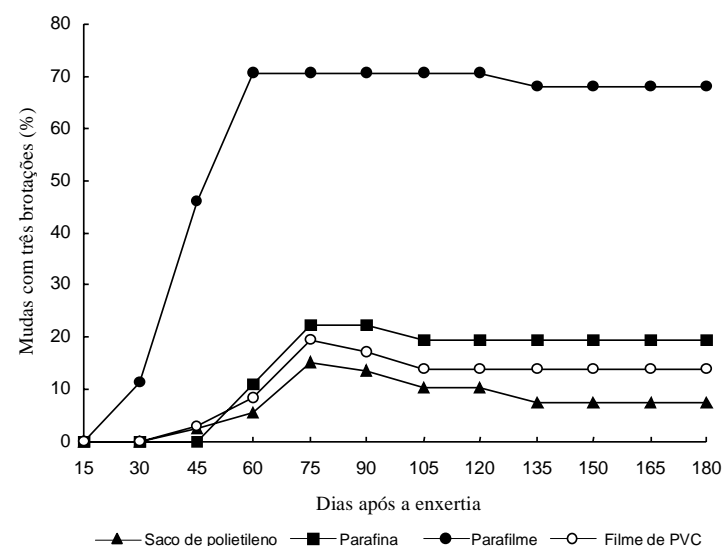

FIG. 1. Porcentagem de mudas com três brotações em razão de diferentes tipos de proteção do enxerto, em nogueira-macadâmia 'Kau 344'.

damente o fluxo de seiva entre as partes envolvidas na união do enxerto. O rápido pegamento da enxertia é fundamental para o sucesso da operação, considerando que isto diminui o período em que o enxerto fica exposto aos riscos da desidratação (Hartmann et al., 1990).

Pelos resultados obtidos, fica evidenciado que, além do saco de polietileno tradicionalmente utilizado para a proteção dos garfos de mangueira após a enxertia, outros materiais podem ser utilizados para a mesma função, como o parafilme ou o filme de PVC, que também evitam a desidratação do enxerto e proporcionam bom pegamento e desenvolvimento do enxerto. Para o abacateiro, o parafilme e o filme de PVC devem ser preferidos, por proporcionarem melhores resultados de pegamento e desenvolvimento dos enxertos. Estes materiais são fáceis de aplicar, podendo ser colocados antes da enxertia ou imediatamente após. Para a nogueira-macadâmia, indica-se o parafilme, que deve ser a opção preferida para a proteção do enxerto.

\section{CONCLUSÕES}

1. Os melhores materiais para a proteção do enxerto da mangueira 'Tommy Atkins' são: o parafilme, o filme de PVC e o saco de polietileno.
2. Para a enxertia do abacateiro 'Fortuna', o parafilme e o filme de PVC constituem os melhores materiais para a proteção do enxerto.

3. Para a nogueira-macadâmia 'Kau 344', o parafilme é o melhor material de proteção do enxerto.

4. A parafina, a parafina + vaselina e a cera de abelha não são efetivas na proteção do enxerto durante a formação de mudas das cultivares estudadas.

\section{REFERÊNCIAS}

BROWSE, P.M. A propagação das plantas. 2.ed. Mem Martins : Europa-América, 1979. p.210-226.

BRUCKNER, C.H.; COSTA, F.O.M. da; PINHEIRO, R.V.R.; ANDERSEN, O. Propagação da macadâmia por meio da enxertia. In: SÃO JOSÉ, A.R. (Ed.). Macadâmia: tecnologia de produção e comercialização. Vitória da Conquista : Universidade Estadual do Sudoeste da Bahia-Departamento de Fitotecnica e Zootecnia, 1991. 224p.

CUNHA, G.A.P.; SAMPAIO, J.M.M.; NASCIMENTO, A.S.; SANTOS FILHO, H.P.; MEDINA, V.M. Manga para exportação: aspectos técnicos da produção. Brasília : Embrapa-SPI, 1994.35p. (Publicações Técnicas Frupex, 8).

DAVIES JUNIOR, F.T.; HAMBRICK, C.E.; FANN, Y.; PEMBERTON, N.B. Grafting and adventitious root formation of Texas field rose bushes. Acta Horticulturae, Leuven, n.189, p.89-100, 1986.

FAUST, M. Physiology of temperate zone fruit trees. New York : J. Wiley, 1989. 338p.

HARTMANN, N.T.; KESTER, D.E.; DAVIES JUNIOR, F.T. Plant propagation: principles and practices. 5.ed. Englewood Cliffs : Prentice Hall, 1990. 647p.

SAMPAIO, J.M.M. Instruções práticas para a produção de mudas de mangueira. 2.ed. Cruz das Almas :Embrapa-CNPMF, 1990.21p. (Embrapa-CNPMF. Circular Técnica, 10).

SIMÃO, S. Tratado de fruticultura. Piracicaba : FEALQ, 1998. 760p.

WHITE, G.; LOWE, W.J.; WEIGHT, J. Paraffin grafting techniques for loblolly pine. Southern Journal of Applied Forestry, Bethesda, v.7, n.3, p.116-118, 1983. 